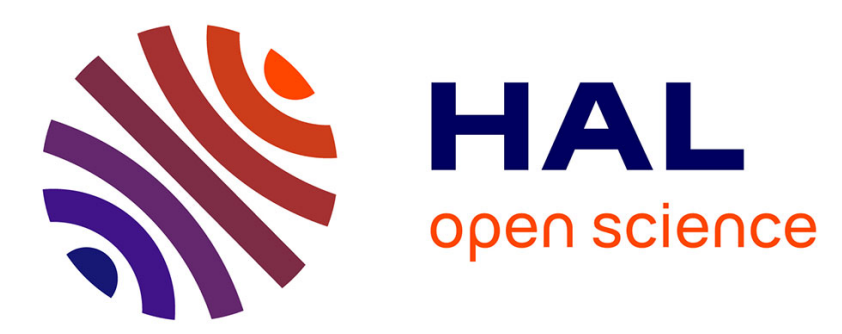

\title{
Dental morphology and wear pattern of bamboo rats, genus Rhizomys (Rodentia: Spalacidae)
}

\author{
Raquel López-Antoñanzas
}

\section{To cite this version:}

Raquel López-Antoñanzas. Dental morphology and wear pattern of bamboo rats, genus Rhizomys (Rodentia: Spalacidae). Zoologischer Anzeiger - A Journal of Comparative Zoology, 2013, 253 (2), pp.85 - 92. 10.1016/j.jcz.2013.09.003 . hal-01920782

\section{HAL Id: hal-01920782 \\ https://hal.science/hal-01920782}

Submitted on 28 Dec 2020

HAL is a multi-disciplinary open access archive for the deposit and dissemination of scientific research documents, whether they are published or not. The documents may come from teaching and research institutions in France or abroad, or from public or private research centers.
L'archive ouverte pluridisciplinaire HAL, est destinée au dépôt et à la diffusion de documents scientifiques de niveau recherche, publiés ou non, émanant des établissements d'enseignement et de recherche français ou étrangers, des laboratoires publics ou privés. 


\section{Elsevier Editorial System(tm) for Zoologischer Anzeiger Manuscript Draft}

Manuscript Number: JCZ-D-13-00046R2

Title: Dental morphology and wear pattern of the bamboo rats Rhizomys Gray, 1831 (Rodentia: Spalacidae)

Article Type: Original Paper

Keywords: Mammalia; Rhizomyinae; Rhizomyini; systematics; dental wear pattern

Corresponding Author: Dr. Raquel López-Antoñanzas, Ph. D.

Corresponding Author's Institution: Museo Nacional de Ciencias Naturales-CSIC

First Author: Raquel López-Antoñanzas, Ph. D.

Order of Authors: Raquel López-Antoñanzas, Ph. D.

Abstract: Rhizomys, one of the most derived genera within the tribe Rhizomyini (Rhizomyinae, Spalacidae, Rodentia), comprises three species: Rhizomys sinensis Gray, 1831, R. pruinosus Blyth, 1851 and R. sumatrensis (Raffles, 1821). A detailed description of the morphology and wear pattern of the cheek teeth of this taxon is provided based on the study of 41 skulls. The variability tracked is due primarily to wear, control of which facilitates comparison of different individuals, fossil or not, at different wear stages. For the first lower and upper molars, six stages of wear (0-5) are recognized. The second lower and upper molars show five stages of wear (0-4), whereas the third ones have four (0-3). The dental wear pattern in Rhizomys is comparable to that of the Pliocene Brachyrhizomys shansius Teilhard de Chardin, 1942. 


\title{
Dental morphology and wear pattern of the bamboo rats
}

\section{Rhizomys Gray, 1831 (Rodentia: Spalacidae)}

\author{
Raquel López-Antoñanzas \\ Departamento de Paleobiología, Museo Nacional de Ciencias Naturales-CSIC, c/ José \\ Gutiérrez Abascal 2, Madrid 28006, Spain \\ E-mail address: ralopan@mncn.csic.es
}

\begin{abstract}
Rhizomys, one of the most derived genera within the tribe Rhizomyini (Rhizomyinae, Spalacidae, Rodentia), comprises three species: Rhizomys sinensis Gray, 1831, R. pruinosus Blyth, 1851 and $R$. sumatrensis (Raffles, 1821). A detailed description of the morphology and wear pattern of the cheek teeth of this taxon is provided based on the study of 41 skulls. The variability tracked is due primarily to wear, control of which facilitates comparison of different individuals, fossil or not, at different wear stages. For the first lower and upper molars, six stages of wear (0-5) are recognized. The second lower and upper molars show five stages of wear (0-4), whereas the third ones have four $(0-3)$. The dental wear pattern in Rhizomys is comparable to that of the Pliocene Brachyrhizomys shansius Teilhard de Chardin, 1942.
\end{abstract}

Keywords: Mammalia; Rhizomyinae; Rhizomyini; systematics; dental wear pattern 


\section{Introduction}

Rhizomyini is a tribe of spalacid rodents within the subfamily Rhizomyinae (see Flynn, 2009; López-Antoñanzas et al., 2013). The name was created by Winge (1887), who regarded this taxon as within the Muridae. McKenna and Bell (1997) considered the rhizomyines a subfamily within the Muridae, subdivided into two tribes: the Rhizomyini and the Tachyoryctini. According to them, the Rhizomyini includes 5 genera (Brachyrhizomys Teilhard de Chardin, 1942, Anepsirhizomys Flynn, 1982, Pararhizomys Teilhard de Chardin and Young, 1931, Rhizomys Gray, 1831 and Cannomys Thomas, 1915). However, the genus Pararhizomys has a different and more simplified molar pattern so that it was excluded from the group (Flynn, 1982a, 2009; Wei et al., 2004; Zhang et al., 2005), even though it was considered a rhizomyid by some authors (Kowalski, 1968). For Flynn (2009), the extinct and extant genera Miorhizomys Flynn, 2009 (formerly attributed to Brachyrhizomys and before that, to Rhizomyoides Bohlin, 1946; see Flynn, 1982, 1990), Cannomys and Rhizomys are members of the Rhizomyini, whereas the genus Anepsirhizomys is of unclear affinities. The results of a recent cladistic analysis involving fossil and living species of the whole subfamily (López-Antoñanzas et al., 2013) has revealed that the tribe Rhizomyini is constituted by the extinct Miorhizomys pilgrimi (Hinton, 1933) and Brachyrhizomys shansius (Teilhard de Chardin, 1942) and the extant Cannomys badius (Hodgson, 1841), Rhizomys sinensis Gray, 1831, R. pruinosus Blyth, 1851 and R. sumatrensis (Raffles, 1821). The origin of the Rhizomyini is to be found at the beginning of the Late Miocene in a Miorhizomys-like form (López-Antoñanzas et al., 2013). Some of its most derived members belong to the genus Rhizomys Gray, 1831. Musser \& Carleton (1993: 685, 2005: 913-915) provided a census of the extant species of Rhizomys recognized as valid (see also Ellerman and Morrison-Scott 
1951: 550-553, 1966: 521-522). They concluded that 3 species of Rhizomys are well defined at present: Rhizomys sinensis, $R$. pruinosus and $R$. sumatrensis. These species live in China, northern and northeastern India, Nepal, Bhutan, southeastern Bangladesh, Myanmar, Laos, Thailand, Cambodia, Vietnam, Malaysia and Sumatra, where they are known from a wide variety of habitats, from bamboo forest to cultivated land, and up to $4000 \mathrm{~m}$ in elevation (IUCN, 2010).

The dental morphology of fossil Rhizomyini has been described in detail (Black, 1972; Flynn, 1982a, 1982b, 2009; Flynn et al., 1990) and that of the extant Cannomys as well (López-Antoñanzas, 2012). However, it has not been adequately described in any modern representative of Rhizomys. Thus, the aim of the present paper is to provide an in-depth description of the dental morphology and dental wear pattern in Rhizomys, a genus whose species endure a high rate of dental abrasion.

Examining the dental wear patterns in extant animals and comparing them with those of their fossil relatives is useful in more than one respect. First, it helps preventing the assignment of fossil teeth from conspecific individuals at different stages of wear (and therefore appearance) to different species. Because the study of dental wear patterns allows determining the relative age of fossil individuals, it permits inferring the age-class structure of the fossil sample to which they belong. A good knowledge of the dental wear pattern makes it also possible to compare the hypsodonty in teeth of individuals belonging to different species. Finally, tooth-wear classes come in handy in cranial morphometric analyses so as to compare individuals of the same ontogenetic age (see e.g., Nicolas et al., 2010).

\section{Material and Methods}


The study presented below is based on the examination of original specimens, casts, and data from the literature. We examined the following: skulls of extant Rhizomys sinensis (ZMB 16768, ZMB 17413, ZMB 45362, ZMB 43372, ZMB 43373, ZMB 17411, ZMB 16770, ZMB 17417, ZMB 16766 in the MB and C.G.1934-1237, C.G.1912-851 in the MNHN), $R$. pruinosus (MNHN DH. 280, MNHN C.G. 1929-259, MNHN C.G. 1929-261, MNHN C.G.1892-1360, MNHN C.G. 1929-263, MNHN C.G.1958-724, MNHN C.G.1962-2297, MNHN C.G.1962-2295, MNHN C.G. 1929-266, MNHN C.G. 1929-272, MNHN C.G. 1929260, MNHN C.G. 1929-267, MNHN C.G. 1993-48, MNHN C.G. 1929-264, MNHN C.G. 1937-1251, MNHN C.G. 1929-265, MNHN C.G. 1929-270, MNHN C.G. 1929-340, MNHN C.G. 1993-02 in the MNHN), R. sumatrensis (ZMB 1847, ZMB A1316, ZMB 38840, ZMB 48085, ZMB 21249 in the MB C.G.1993-49, MNHN C.G. 1962-2294, MNHN C.G. 2007162, MNHN C.G. 1980-235, MNHN A 7.216, MNHN A7.215 in the MNHN), and isolated teeth, maxillary fragments and mandible fragments of the following extinct species: Miorhizomys pilgrimi (lower incisor AMNH 39327 and cast of D-278 in the BSP) and Brachyrhizomys shansius (cranium and mandible AMNH 117337).

First, second and third lower molars are designated as $\mathrm{m} 1, \mathrm{~m} 2$ and $\mathrm{m} 3$, respectively, and first, second and third upper molars as M1, M2 and M3. The terminology used in the tooth descriptions follows the rodent dental terminology of Flynn (1982a) with some adjustments (see Fig. 1).

Abbreviations: AMNH: American Museum of Natural History, New York, USA; BMNH: Natural History Museum, London, United Kingdom; C.G.: Catalogue général du Laboratoire des Mammifères et Oiseaux, MNHN, Paris, France; GSI: Geological Survey of India, Kolkata, India; IVPP, Institute of Vertebrate Paleontology and Paleoanthropology, Beijing, China; MNHN: Muséum national d'Histoire naturelle, Paris, France; Y-GSP: Yale- 
Geological Survey of Pakistan, Quetta, Pakistan; ZMB: Zoologische Sammlung, Museum für Naturkunde der Humboldt-Universität, Berlin, Germany.

\section{Systematics}

Genus Rhizomys Gray, 1831

Type species. Rhizomys sinensis Gray, 1831

Referred species. Rhizomys pruinosus, Rhizomys sumatrensis

Rhizomys sinensis Gray, 1831

Gray, on the basis of a skull and skin brought from China by Mr. Reeves, recognized the new genus and new species of rodent Rhizomys sinensis in 1831. The brief Latin diagnosis he gave (Gray, 1831: 95):“Rhiz. pallidè cinerascens unicolor" can be translated as follows:

"Rhiz. pale ash-grey single-colored". The type specimens are BMNH 49b (skin) and BMNH 1161a (skull) (P. Jenkins, pers. comm. 2012).

The molars of Rhizomys sinensis are short rooted and lack the mure. They show unilateral hypsodonty and a strong wear gradient in which the first molars are well worn by the time the third molars erupt (Fig. 3A-B). No individuals of $R$. sinensis were observed with 2 nd molars still in crypts and third molars below the bone; first molars would be in wear stage 0 or 1 in these cases. The orange upper incisors are recurved and ventrally directed and lack major ornamentation. 


\section{Upper dentition}

M1. Its occlusal outline is nearly square. This tooth is four rooted with the anterolingual root the most developed. The dental pattern of M1 is tetralophodont with anteroloph, protoloph, mesoloph and metaloph+posteroloph.

In early wear, M3 is just erupting (e.g., C.G.1912-851, ZMB 16768, Figs. 1A and 2A). The anteroloph of M1 connects lingually to the protoloph through the protocone and labially to the protoloph, isolating an anterior enamel lake. At this point, the mesoloph, which is a long continuation of the hypocone, joins labially the metaloph-posteroloph, isolating a posterior enamel lake, which is larger than the anterior one. The protoloph connects labially to the mesoloph and to the anteroloph. Thus, the tooth has two enamel lakes and a narrow and elongated central reentrant that divides the tooth into two parts. This lingual reentrant extends nearly to the base of the crown and it is transverse in occlusal view. In some specimens (e.g., ZMB 16768) this reentrant is divided into two parts due to the lingual junction between the mesoloph and the protoloph. In this case, a small central enamel lake is isolated. This morphology corresponds to wear stage 2 .

After moderate wear, the morphology of M1 (e.g., ZMB 16760, Fig. 1C) is quite similar to that in the preceding stage. However, M1 is significantly reduced in size and the anteroloph and the protoloph combine, although a remnant of the anterior enamel lake persists (ZMB 16770). At this state, the specimens have the lingual reentrant divided and they show a lingual sinus and two major labial enamel lakes that correspond with the former anterosinus and mesosinus. The lingual sinus is still open and directed towards the central enamel lake. This morphology corresponds to wear stage 3 .

In later wear (stage 4), the posterior enamel lake is reduced (ZMB 43373b, Fig. 2G). The sinus is still lingually open. With more wear, the occlusal surface is completely flat and the 
enamel has disappeared from the labial and posterior borders of the tooth, although it persists on the anterior and lingual sides. The enamel lakes are reduced to small circular labial structures (ZMB 17411) and the lingual reentrant is closed off. This morphology corresponds to wear stage 5 .

M2. It is four rooted with the anterolingual root the most developed. The dental pattern of M2 is tetralophodont: anteroloph, protoloph, mesoloph and metaloph+posteroloph. In early wear (e.g., C.G.1912-851, ZMB 16768, Figs. 1A, 2A), the anteroloph is a long continuation of the protocone and joins labially the protoloph, which does not connect to the protocone. The mesoloph joins the metaloph-posteroloph through the hypocone. The lingual reentrant is confluent with the anterior and middle labial reentrants. The anterior part of the tooth is separated from the posterior one, the mure is lacking. In some specimens, the protoloph connects labially to the anteroloph and the mesoloph (ZMB 16768). This morphology corresponds to wear stage 1 . When M2 is at this point, M1 is at wear stage 2. After moderate wear (e.g., ZMB 16770, Fig. 2C), the protoloph connects to the protocone and two elongated enamel lakes (anterior and posterior) are isolated. The lingual reentrant joins the middle reentrant and extends transversely across the occlusal surface. This morphology is wear stage 2 (wear stage 3 in M1). With more wear, the anterior enamel lake is reduced (e.g., ZMB 43373a and ZMB 43373b, Figs. 2E-G). In some specimens (ZMB 43373b), the protocone connects to the hypocone and divides the long central reentrant into two parts: the lingual sinus and an isolated and elongated central enamel lake. In this case, the tooth has three labial enamel lakes and a lingual reentrant still open. This morphology corresponds to wear stage 3 (wear stage 4 in M1). In later wear (e.g., ZMB 17411, Fig. 2I), the occlusal surface is completely flat and only a small anterolabial enamel lake persists labially. The enamel has 
nearly disappeared from the labial border of the tooth. This is wear stage 4 (wear stage 5 in M1).

M3. This tooth has three roots; the posterior one is the most developed. When unworn (e.g., C.G. 1912-851, ZMB 16768; Figs. 1A, 2A), all the cusps of the tooth are recognizable. This tooth shows a tetralophodont dental pattern with anteroloph, protoloph, mesoloph and a short metaloph+posteroloph. The anteroloph is a long continuation of the protocone, the protoloph and posteroloph are isolated and the mesoloph is divided, with a labial cusp that could be called a mesostyle or hypoloph. The mure is lacking and the lingual re-entrant is confluent with both the anterior and middle labial reentrants. This morphology corresponds to wear stage 0. When M3 is at this point, M1 and M2 are at wear stage 2 and 1, respectively. After moderate wear (e.g., ZMB 16770), the protoloph connects to the anteroloph and nearly connects to the protocone, isolating an elongated anterior enamel lake. The lingual reentrant is confluent with the anterior and middle reentrants. At this wear stage, the mesoloph joins labially both the posteroloph and the mesostyle. Therefore, on the posterior side of the tooth, there is an elongate posterior enamel-lake and a posterolabial re-entrant. This morphology corresponds to wear stage 1 (wear stage 3 in M1 and 2 in M2). In later wear (e.g., ZMB 43373a, ZMB 43373b; Figs. 2E-G), the morphology of M3 is quite similar to that at the previous wear stage. However, the posteroloph is combined with the mesoloph, isolating an elongated posterior enamel lake, and the posterolabial re-entrant has disappeared. This is wear stage 2, which corresponds to wear stage 4 in M1 and 3 in M2. Later, the tooth is completely worn and only a flat surface (devoid of any enamel lake) shows up (e.g., ZMB 17411, see Fig. 2I). This morphology corresponds to wear stage 3 (wear stage 5 and 4 in M1 and M2, respectively). 


\section{Lower dentition}

$m 1$. This tooth is three rooted. It shows a pentalophodont dental pattern with anterolophid, metalophid, mesolophid, hypolophid and posterolophid.

In early wear (e.g., C.G.1912-851, ZMB 16768, ZBM 17417, Figs. 1B, 2B), all labial reentrants but the posterior one are already closed off. The anterolophid is combined with the metalophid, isolating a small anterior circular enamel-lake. The mesolophid connects labially and lingually to the metalophid and hypoconid, respectively. This results in the isolation of a second and elongate enamel-lake. In some specimens (e.g., ZBM 17417), there is an additional connection between the mesolophid and the metalophid at about the midpoint of the tooth. In this case, the second enamel-lake is divided into a small and circular labial enamel-lake and an elongate lingual one. In addition, the mesolophid joins the hypolophid isolating a third enamel-lake, which is confluent with the lingual re-entrant. Thus, the third enamel-lake is very elongate and extends transversely across the occlusal surface of the tooth. The posterolophid joins the hypolophid through the hypoconid, isolating an elongate posterolabial enamel-lake. With slightly more wear (Fig. 2B), the lingual re-entrant is closed off and the enamel disappears from the anterior border of the tooth. This morphology corresponds to wear stage 2. With further wear (stage 3; e.g., ZMB 16770, Fig. 2D), the second enamel-lake is divided and forms a small additional enamel-lake. The posterior reentrant is closed off. At stage 4 (e.g. ZMB 43373b, Fig.2G), the posterolophid and the hypolophid are combined. The posterior enamel-lake has disappeared or is reduced into a small and circular enamel-lake. The only specimen I have seen with further wear (ZMB 17411) is broken but seems to have a flat occlusal surface, nearly completely devoid of enamel. 
$m 2$. This tooth is square in occlusal outline. It has four roots, the posterolingual one being the most developed. It has four major lophs: anterolophid-metalophid, short mesolophid, hypolophid and long posterolophid. The mure is lacking and the posterior part of the tooth is isolated from the anterior one. In early wear (e.g., C.G.1912-851, ZMB 16768, ZMB 17417, see Figs. 1B and 2B), the anterolophid fuses with the metalophid, isolating a small and elongate anterior enamel-lake that disappears quickly with wear. The mesolophid joins labially this first lophid through the protoconid, and the hypolophid and posterolophid are isolated. All re-entrants are open and the labial one is confluent with both the middle and the posterior ones. This morphology corresponds to wear stage 1 (stage 2 in m1). After further wear (e.g. ZMB 16770), the morphology of the tooth is similar to that of the preceding stage, but the hypolophid connects to the posterolophid through the hypoconid, isolating a posterior and elongate enamel-lake, and to the anterolophid-metalophid. All lingual re-entrants are closed off. The labial re-entrant joins the middle enamel-lake. This morphology corresponds to wear stage 2 (wear stage 3 in m1). With further wear (e.g., ZMB 43373a, ZMB 43373b, Fig. 2F-H), the mesolophid connects to the hypolophid, isolating an elongate anterior enamellake. The sinusid is closed off and a labial enamel-lake is formed. This is wear stage 3 (wear stage 4 in $\mathrm{m} 1)$. In later wear (ZMB 17411, Fig. 2J), the tooth is worn flat with some remnant of enamel lakes. This morphology corresponds to wear stage 4, which is coincident with wear stage 5 in $\mathrm{m} 1$.

$m 3$. When unworn (e.g., C.G.1912-851, ZMB 17417), the metalophid is distinct from the anterolophid and connects lingually to it. Both structures will quickly fuse through wear (ZMB 16768; Fig. 2B), isolating a tiny and circular anterolingual enamel lake. The mesolophid, which is cusp-like, is a short continuation of the protoconid. The cusp-like hypolophid and the short posterolophid are isolated. The mure is lacking as the posterior part 
of the tooth is isolated from the anterior one. This morphology corresponds to wear stage 0 (wear stages 2 and $1 \mathrm{in} \mathrm{m} 1$ and $\mathrm{m} 2$, respectively). In early wear (e.g., ZMB 16770), the morphology of the tooth is similar to that at the preceding stage, but the mesolophid and the hypolophid are fused, forming a central lophid. The third lophid is an arcuate structure that is isolated from the rest of the crown by a long re-entrant (the sinusid). This is wear stage 1 (wear stage 3 and 2 in $\mathrm{m} 1$ and $\mathrm{m} 2$, respectively). In advanced wear (e.g., ZMB 43373a, ZMB 43373b; Fig. 2F-H), the $\mathrm{m} 3$ significantly increases in size. The first lingual re-entrant is closed off, isolating an elongate middle enamel-lake. The small circular anterolingual enamel lake persists. This morphology corresponds to wear stage 2 (wear stage 4 and 3 in $\mathrm{m} 1$ and $\mathrm{m} 2$, respectively). In later wear (ZMB 17411, Fig. 2J), the occlusal surface of the tooth is flat. However, it still shows three small enamel lakes: labial and lingual elongate ones and a tiny, circular central one that has persisted through wear. All labial and lingual reentrants are closed off. This morphology corresponds to wear stage 3 , which corresponds to wear stage 5 in $\mathrm{m} 1$ and wear stage 4 in $\mathrm{m} 2$.

Rhizomys sumatrensis (Raffles, 1821)

Raffles (1821: 258) named this species as Mus sumatrensis on the basis of a drawing and a specimen forwarded from Malacca (Malaysia) by W. Farquhar. The reason he chose sumatrensis as a species name when it had not been found in Sumatra remains unknown. Later on, Gray (1831: 95) included M. sumatrensis in the new genus Rhizomys. The type specimen was possibly lost in transit (P. Jenkins, pers. comm. 2012).

The teeth of Rhizomys sumatrensis and $R$. sinensis are quite similar, but some differences can be discerned. The molars of $R$. sumatrensis are high crowned, although not as much as 
those of $R$. sinensis, and they have longer roots and much smaller M3 than $R$. sinensis.

Furthermore, M1 of R. sumatrensis is the largest tooth, whereas it is M2 in R. sinensis.

The dental wear pattern of Rhizomys sumatrensis is comparable to that in $R$. sinensis. Newborn and infant individuals of R. sumatrensis (Fig. 3 A-D) were available in the collections of the MNHN (whereas such specimens were lacking for $R$. sinensis). The examination of these specimens allows describing wear stage 0 and 1 in the genus Rhizomys. In addition, due to the different morphology of M3 in $R$. sumatrensis with respect to the remaining congeneric species, the wear pattern of this tooth is also described in detail.

\section{Upper dentition}

M1. It is the only visible tooth in a new born skull of Rhizomys sumatrensis (A 7.216, Fig. 3B). It shows a basic pentalophodont dental pattern with anteroloph, protoloph, mesoloph, metaloph and posteroloph. When unworn, the protoloph is isolated, the mesoloph is a long continuation of the hypocone and the metaloph does not join with the hypocone but with the posteroloph labially. All re-entrants, but the posterior one, are open. This morphology corresponds to wear stage 0 . In specimens in which M3 are still in their crypts (e.g., A 7.215; Fig. 1D), the metaloph is fused with the posteroloph and only four crests are recognizable: anteroloph, protoloph, mesoloph and metaloph-posteroloph. At this state of wear, the anteroloph is a long continuation of the protocone, the protoloph is still secluded, the posterior part of the tooth is isolated from the rest of the crown by a long and continuous sinus (the mure is lacking), the mesoloph is a long continuation of the hypocone and the posteroloph connects to the hypocone. All labial and lingual re-entrants are still open. This morphology corresponds to wear stage 1. 
M2. The morphology of M2 in specimen A 7.215 (Fig. 1D) is quite similar than that of M1. However, the anterior part of M2 is antero-posteriorly compressed. As in M1, M2 has four major crests (anteroloph, protoloph, mesoloph and metaloph-posteroloph). The anteroloph and the protoloph unite with the protocone and the mesoloph and the metaloph-posteroloph join with the hypocone. The mesoloph is a long continuation of the hypocone. The anterior part of the tooth is isolated from the posterior one by a long, transversal sinus dividing the tooth into two parts (the mure is absent). This morphology corresponds to wear stage 0 . When M2 is at this point, M1 is at wear stage 1.

M3. This tooth is three rooted, the anterolingual one being the most developed. When unworn (e.g., MNHN C.G. 2007-162, Fig. 3E), M3 shows a tetralophodont dental pattern with anteroloph, protoloph, mesoloph and short posteroloph. At this state, the anteroloph joins the protocone, the mesoloph is divided with a distinct mesostyle and the mure is lacking. This morphology corresponds to wear stage 0 . When M3 is at this point, M1 and M2 are at wear stage 2 and 1, respectively. After moderate wear (ZMB 38840, Fig. 3G), the lingual re-entrant is closed off; it is confluent with the labial reentrant that is still open. At this point, the anteroloph joins the protoloph and protocone and the mesoloph connects to the posteroloph, isolating a small and circular posterior enamel-lake. This is wear stage 1. In later wear (ZMB 21249; Fig. 3I), all re-entrants are closed off. The fusion of the anteroloph with the protoloph isolates an anterior enamel lake and that of the mesoloph with the posteroloph, a posterior enamel lake. In addition, the anteroloph-protoloph joins the mesoloph-posteroloph, isolating a third elongate lingual enamel-lake (ZMB 21249). The anterior and lingual enamel-lakes can also combine into a single one (ZMB 1847). This morphology corresponds to wear stage 2 (wear stage 4 and 3 in M1 and M2, respectively). 
Lower molars. The molars of this species are high crowned, although not as much as in Rhizomys sinensis, and with longer roots than in the latter.

$m 1$. This tooth is three rooted with the anterior root the most developed. When unworn (e.g., A. 7.216; Fig. 3A), the m1 shows a basic pentalophodont dental pattern: anterolophid, metalophid, mesolophid, hypolophid and posterolophid. The anterolophid is connected lingually to the metalophid. This anterior loph is isolated from the rest of the tooth by a long sinusid. The mesolophid is a long continuation of the protoconid; it is isolated. The hypolophid loosely connects to the hypoconid. The posterolophid is an arcuate continuation of the hypoconid. At this wear stage, all re-entrants, except for the most anterolingual one, remain open. This morphology corresponds to wear stage 0 .

In early wear (stage 1; e.g., A. 7.215, Fig. 3C), the morphology of $\mathrm{m} 1$ is quite similar to that at the preceding wear stage. However, the metalophid joins the anterolophid labially. In addition, the mesolophid slightly connects to the hypolophid, which otherwise would be completely isolated. The former is divided with a distinct mesostylid.

$m 2$. This tooth is four rooted; the posterolingual one being the most developed. In specimen A-7.215 (with unerupted $\mathrm{m} 3$ ), $\mathrm{m} 2$ is unworn (Fig. 3C). It has five lophs: anterolophid, metalophid, short mesolophid, hypolophid and posterolophid. Both lingual and labial anterolophid are distinct. The lingual anterolophid joins the metalophid, isolating a small enamel-lake in the anterolingual corner of the tooth, which is quickly lost through wear. The short mesolophid connects to the labial anterolophid. The hypolophid as well as the arcuate posterolophid are isolated. All labial and lingual sinusids remain open. This morphology is wear stage 0 . When $\mathrm{m} 2$ is at this wear stage, $\mathrm{m} 1$ is at its first stage of wear. In early wear (e.g., MNHN C.G. 2007-162; Fig. 3F), metalophid and anterolophid are fused in 
one major anterior loph that joins the mesolophid through the protoconid. Hypolophid and posterolophid are still isolated and the labial sinusid is confluent with both the anterior and posterior lingual re-entrants. This is wear stage 1 , and at this point $\mathrm{m} 1$ is at stage 2 .

$m 3$. This tooth is three rooted with the posterior root the most developed. When unworn (e.g., MNHN C.G. 2007-162; Fig. 3F), it shows anterolophid, metalophid, very short mesolophid, hypolophid and posterolophid. At this wear stage, the anteroconid and the labial and lingual anterolophids are distinct. The lingual anterolophid joins the metalophid, isolating a small enamel-lake on the anterolingual corner of the tooth. The mure is absent and all labial and lingual sinusids remain open. This is wear stage 0. When $\mathrm{m} 3$ is at this stage of wear, $\mathrm{m} 1$ and $\mathrm{m} 2$ are at their second and first ones, respectively. In early wear (ZMB 38840; Fig. 3H), metalophid and anterolophid fuse, isolating a small anterolingual enamel-lake. This first loph joins labially the second loph, which is formed by the junction of the mesolophid with the hypolophid. The arcuate posterolophid is isolated. The mure is lacking. All labial and lingual reentrants are still open. This morphology corresponds to wear stage 1 (wear stage 3 and 2 in m1 and m2, respectively). After moderate wear (e.g., ZMB 1847, ZMB 21249; Fig. 3J), the morphology of the tooth remains quite similar to that at the previous wear stage. However, the lingual and labial re-entrants are closed off. This morphology is wear stage 2 (wear stage 4 and 3 in $m 1$ and $m 2$, respectively).

Rhizomys pruinosus Blyth, 1851

This species was named by Blyth (1851: 519) after the examination of a few specimens from the Khásia Hills (Chérra Punji, Bangladesh). Blyth differentiated this species from $R$. sumatrensis in being "much less robust, having a much shorter tail, and a dense coat of fine 
soft fur instead of a thin coat of bristly fur". However, he pointed out that their structural characters were essentially the same. A thorough examination of the teeth of this taxon has revealed a few differences with respect to Rhizomys sinensis and $R$. sumatrensis. M1 of $R$. pruinosus is longer than wide, whereas the occlusal outline in $R$. sumatrensis and $R$. sinensis is square. M3 of $R$. pruinosus is not as small as that of $R$. sumatrensis. In addition, M1 in $R$. pruinosus is much more reduced through wear than in $R$. sumatrensis but somewhat less than in $R$. sinensis. The dental wear pattern of $R$. pruinosus (Fig. 4A-N) is comparable to that in $R$. sinensis (see above).

\section{Discussion and conclusion}

The study of 41 skulls of extant Rhizomys has allowed me to determine the changes in dental wear pattern throughout life in this taxon. For the first lower and upper molars, six stages of wear (0-5) are recognized. The second lower and upper molars show five stages of wear $(0-4)$, whereas the third ones have four $(0-3)$. Wear stage 0 of the first lower and upper molars, in which the second molars are still in their crypts, is that of new-born individuals. Wear stage 0 of the second lower and upper molars (wear stage 1 of the first ones) corresponds to infants, in which the third molars have not erupted from the jaw bone yet. Wear stage 0 of the third lower and upper molars (wear stages 2 and 1 of the first and second ones, respectively), is that of juvenile individuals. Finally, wear stages 3-5 of the first molars (2-4 of the second molars and 1-3 of the third ones) are found in adult individuals.

The tribe Rhizomyini comprises the extant species belonging to the genera Rhizomys and Cannomys but also the extinct Miorhizomys pilgrimi and Brachyrhizomys shansius (see López-Antoñanzas et al., 2013). M. pilgrimi is a basal member of the tribe. Remains of this 
taxon have been found in Late Miocene lower alternations in Haritalyangar, India (Hinton, 1933), in the Dhok Pathan Formation in the Potwar Plateau, Pakistan (Flynn, 1982a) and at the coeval Chinese locality of Lufeng (Flynn \& Qi, 1982). All of them correspond to adult individuals. The morphology of the teeth of the specimens GSI HT6 (a hemimandible with m1-m3, Fig.5A), GSI D270 (Fig.5B) and YGSP 8366 (mandible fragments with m2-m3, Fig.5C) correspond to wear stages 3, 2, 1 for the $\mathrm{m} 1, \mathrm{~m} 2$ and $\mathrm{m} 3$, respectively. YGSP 182 (a mandible fragment with $\mathrm{m} 2-\mathrm{m} 3$ ) is more worn (Fig. 5D); $\mathrm{m} 2$ of YGSP 182 is at wear stage 3 and the morphology of the $\mathrm{m} 3$ corresponds to wear stage 2 .

Brachyrhizomys shansius, the sister species of the crown-group, has been recorded from several Pliocene localities of the Yushe Basin, Shanxi, China (Teilhard de Chardin, 1942; Flynn, 1993; Flynn, 2009). This species was regarded as a primitive type of Rhizomys and included in it as a subgenus by Flynn (2009). However, a cladistic analysis of the whole subfamily Rhizomyinae supports the reestablishment of the genus Brachyrhizomys (LópezAntoñanzas et al., 2013). The dental wear pattern of B. shansius (Fig. 5) is comparable to that of the extant Rhizomys (Fig. 4). The dental wear morphology of the juvenile B. shansius (AMNH 117337; Fig. 5E-F), in which the third molars are just erupting, corresponds to wear stages 2, 1 and 0 for the first, second and third molars, respectively. Its wear pattern is similar to that of juvenile individuals of $R$. pruinosus (e.g., ZMB 17417; Fig. 4E-F).

Nevertheless, B. shansius has more marked upper molar wear than $R$. pruinosus. Thus, M1 and M2 of B. shansius are more worn than those of $R$. pruinosus at the same wear stage (Figs. 4A and 5A). The figured (Teilhard de Chardin, 1942; Flynn, 1993) individuals of B. shansius (specimens 31095 and 31096; Fig; 5G-I and specimen 14183; Fig. 5H) are adult. The morphology of 31095 (Fig. 5G) corresponds to the wear stage 3 for the first molars, 2 for the second and 1 for the third. Specimens 31096 and 14183 are at wear stages 2, 3 and 4 for their $\mathrm{m} 3, \mathrm{~m} 2$ and $\mathrm{m} 1$, respectively (Fig. 5H-I). 


\section{Acknowledgements}

I sincerely thank C. Denys (Muséum National d'Histoire Naturelle, Paris), F. Mayer and N. Lange (Museum für Naturkunde der Humboldt-Universität, Berlin), G. Rößner (Staatssamlung für Paläontologie und Geologie, Munich), and J. Galkin, J. Meng, R. O’Leary and C. Mehling (American Museum of Natural History, New York) for having made available the rhizomyine material under their care. P. Jenkins (The Natural History Museum, London) answered my inquiries. A. Kupfer (Universität Potsdam, Golm), L.J. Flynn (Harvard University, Cambridge) and anonymous reviewers enhanced this work through critical reading. My sojourns in Munich and Paris were funded by the Alexander von Humboldt Foundation through sponsorships of renewed research stays in Germany and by the EDIT Gender Action Plan, respectively. This research received support from the SYNTHESYS Project (http://www.synthesys.info/), which is financed by European Community Research Infrastructure Action under the FP7 "Capacities" Program. I am currently supported by the Ramón y Cajal Program and the research project CGL2011-24829, of which I am PI.

\section{References}

Black, C.C., 1972. Review of fossil rodents from the Neogene Siwalik Beds of India and Pakistan. Palaeontol. 15, 238-266.

Blyth, E., 1851. Notice of a collection of Mammalia, Birds, and Reptiles, procured at or near the station of Chérra Punji in the Khásia hills, north of Sylhet. J. Asiat. Soc. Bengal 20, $517-524$. 
Bohlin, B., 1946. The fossil mammals from the Tertiary deposits of Taben-Baluk, Western Kansu, Part II: Simplicidentata, Carnivora, Artiodactyla, Perissodactyla, and Primates. Palaeontol. Sin. C 8b, 1-259.

Ellerman, J.R., Morrison-Scott, T.C.S., 1951. Checklist of Palaearctic and Indian Mammals, 1758 to 1946, First Edition. British Museum (Natural History), London.

Ellerman, J.R., Morrison-Scott, T.C.S., 1966. Checklist of Palaearctic and Indian Mammals, 1758 to 1946, Second Edition. British Museum (Natural History), London.

Flynn, L.J., 1982a. Systematic revision of Siwalik Rhizomyidae (Rodentia). Geobios 15, 327389.

Flynn, L.J., 1982b. A revision of fossil rhizomyid rodents from northern India and their correlation to a rhizomyid biochronology of Pakistan. Geobios 15, 583-588.

Flynn, L.J., 1990. The natural history of rhizomyid rodents. In: Nevo, E., Reig O.A. (Eds.), Evolution of Subterranean Mammals at the Organismal and Molecular Levels. A.R. Liss, New York, pp. 155-183.

Flynn, L.J., 1993. A new bamboo rat from the Late Miocene of Yushe Basin. Vert. Palasiatica $31,95-101$.

Flynn, L.J., 2009. The antiquity of Rhizomys and independent acquisition of fossorial traits in subterranean muroids. Bull. Am. Mus. Nat. Hist. 331, 128-156.

Flynn, L.J., Qi, G., 1982. Age of the Lufeng, China, hominoid locality. Nature 298, 746-747.

Flynn, L.J., Sahni, A., Jaeger, J.J., Singh, B., Bhatia, S.B., 1990. Additional fossil rodents from the Siwalik Beds of India. Proc. Kon. nederl. Akad. Wetensch. 93, 7-20.

Gray, J.E., 1831. Characters of three new genera, including two new species of Mammalia from China. Proc. Comm. Sci. Corr. Zool. Soc. London 1, 94-98.

Hinton, M.A.C., 1933. Diagnoses of new genera and species of rodents from Indian Tertiary deposits. Ann. Mag. nat. Hist. 12, 620-622. 
Hodgson, B.H., 1841. New species of Rhizomys discovered in Nepal. Calcutta J. Nat. Hist. 2, $60-62$.

IUCN, 2010. IUCN red list of threatened species. Version 2010.1. Available at $\underline{\text { www.iucnredlist.org }}$

Kowalski, K., 1968. Pararhizomys hipparionum Teilhard \& Young, 1931 (Rodentia) from the Pliocene of Altan Tell, Western Mongolia. Palaeontol. Pol. 19, 163-168.

López-Antoñanzas, R., 2012. Dental morphology of the Lesser Bamboo Rat (Rodentia, Spalacidae). Zookeys 228, 69-75.

López-Antoñanzas, R., Flynn, L.J., Knoll, F., 2013. A comprehensive phylogeny of extinct and extant Rhizomyinae (Rodentia): evidence for multiple intercontinental dispersals. Cladistics 29, 247-273.

McKenna, M.C., Bell, S.K., 1997. Classification of Mammals above the Species level. Columbia University Press, New York.

Musser, G.G., Carleton, M.D., 1993. Family Muridae. In: Wilson, D.E., Reeder, D.M. (Eds.), Mammal Species of the World, Second Edition. The Johns Hopkins University Press, Baltimore, pp. 501-755.

Musser, G.G., Carleton, M.D., 2005. Superfamily Muroidea. In: Wilson, D.E., Reeder, D.M. (Eds.), Mammal Species of the World, Third Edition. The Johns Hopkins University Press, Baltimore, pp. 894-1531.

Nicolas, V., Akpatou, B., Wendelen, W., Kerbis Peterhans, J., Olayemi, A., Decher, J., Missoup, A.D., Denys, C., Barrière, P., Cruaud, C., Colyn, M., 2010. Molecular and morphometric variation in two sibling species of the genus Praomys (Rodentia: Muridae): implications for biogeography. Zool. J. Linn. Soc. 160, 397-419.

Raffles, T.S., 1821. Descriptive Catalogue of a Zoological Collection. Trans. Linn. Soc. London 13, 239-274. 
Teilhard de Chardin, P., Young, C.C., 1931. Fossil mammals from the Late Cenozoic of Northern China. Palaeontol. Sin. 9, 1-88.

Teilhard de Chardin, P., 1942. New rodents of the Pliocene and lower Pleistocene of north China. Pub. Inst. Géo-Biol. 9, 1-101.

Thomas, O., 1915. Notes on the Asiatic Bamboo-Rats (Rhizomys, etc.). Ann. Mag. Nat. Hist. $16,56-61$.

Wei, G., Kawamura, Y., Jin, C., 2004. A new bamboo rat from the Early Pleistocene of Renzidong Cave in Fanchang, Anhui, Central China. Quaternary Res. 43, 49-62.

Winge, H., 1887. Jordfundne og nulevende Gnavere (Rodentia) fra Lagoa Santa, Minas Geraes, Brasilien. E Museo Lundii, University of Copenhagen 1: 1-178.

Zhang, Z., Flynn, L.J., Qiu, Z., 2005. New Materials of Pararhizomys from Northern China, Palaeontol. Electron. 8 (1), 5A. 
Fig. 1. Rhizomyini dental terminology used in this paper. Rhizomys sinensis (MNHN C.G. 1912-851). A. Right maxilla with M1-M3. B. Left mandible with m1-m3. Scale bar equals 2 $\mathrm{mm}$.

Fig. 2. Dental wear pattern in Rhizomys sinensis. A-B. Stage of wear 2,1 and 0 for the first, second and third upper and lower molars, respectively, juvenile individual (ZMB 16768). A. Right maxilla with M1-M3. B. Right hemimandible with m1-m3. C-D. Stage of wear 3, 2 and 1 for the first, second and third upper and lower molars respectively, adult individual (ZMB 16770). C. Right maxilla with M1-M3. D. Right hemimandible with m1-m3. E-H. Stage of wear 4, 3 and 2 for the first, second and third upper and lower molars, respectively, adult specimens (ZMB 43373a and ZMB 43373b). E. Right maxilla with M2-M3. F. Right hemimandible with m1-m3. G. Right maxilla with M1-M2. H. Right hemimandible with m1m3. I-J. Stage of wear 5, 4 and 3 for the first, second and third upper and lower molars, respectively, adult individual (ZMB 17411). I. Right maxilla with M1-M3. J. Right hemimandible with $\mathrm{m} 2-\mathrm{m} 3$. Scale bar equals $5 \mathrm{~mm}$.

Fig. 3. Dental wear pattern in Rhizomys sumatrensis. A-B. Stage of wear 0, new-born individual (A. 7. 216). A. Left $\mathrm{m} 1$ in occlusal view. B. Right M1 in occlusal view. C-D. Stage of wear 1 and 0 for the first and second upper and lower molars, respectively, infant (A. 7. 215). C. Left hemimandible with m1-m2. D. Right maxilla with M1-M2. E-F. Stage of wear 2, 1 and 0 for the first, second and third upper and lower molars, respectively, juvenile individual (MNHN C.G. 2007-162). E. Right maxilla with M1-M3. F. Left hemimandible with m1-m3. G-H. Stage of wear 3, 2 and 1 for the first, second and third upper and lower molars, respectively, adult individual (ZMB 38840); G. Right maxilla with M1-M3. H. Left hemimandible with m1-m3. I-J. Stage of wear 4, 3 and 2 for the first, second and third upper 
and lower molars, respectively, adult individual (ZMB 21249). I. Left Maxilla with M1-M3. J. Left hemimandible with m1-m3. Scale bar equals $5 \mathrm{~mm}$.

Fig. 4. Dental wear pattern in Rhizomys pruinosus. A-C. Stage of wear 0, new-born individual (MNHN DH 280). A. Right $\mathrm{m} 1$ in occlusal view. B. Left $\mathrm{m} 1$ in occlusal view. C. Left M1 in occlusal view. D. Right M1 in occlusal view. E-F. Stage of wear 2, 1 and 0 for the first, second and third upper and lower molars, respectively, juvenile individual (ZMB 17417). E. Right maxilla with M1-M3. F. Right hemimandible with m1-m3. G-H. Stage of wear 3, 2 and 1 for the first, second and third upper and lower molars, respectively, adult individual (MNHN C.G. 1962-2295). G. Left maxilla with M1-M3. H. Right hemimandible with m1m3. I-J. Stage of wear 3, 2 and 1 for the first, second and third upper and lower molars, respectively, adult individual (MNHN C.G. 1962-2297). I. Left maxilla with M1-M3. J. Left hemimandible with m1-m3. K-L. Stage of wear 4, 3 and 2 for the first, second and third upper and lower molars, respectively, adult individual (MNHN C.G. 1962-2294). K. Right maxilla with M1-M3. L. Right hemimandible with m1-m3. M-N. Stage of wear 5, 4 and 3 for the first, second and third upper and lower molars, respectively, adult individual (MNHN C.G. 18921360). M. Right maxilla with M1-M3. N. Right hemimandible with m1-m3. Scale bar equals $5 \mathrm{~mm}$.

Fig. 5. Fossil Rhizomyini. A. Miorhizomys pilgrimi (GSI HT6), left mandible with m1-m3. B. Miorhizomys pilgrimi (GSI D270), right mandible fragment with m2-m3. C. Miorhizomys cf. M. pilgrimi (YGSP 8366), fragment of left $\mathrm{m} 1$ and m2-m3. D. Miorhizomys $\mathrm{cf}$. M. pilgrimi (YGSP 182), left m2-m3. E. Brachyrhizomys shansius (AMNH 117337), right maxilla with M1-M3. F. Brachyrhizomys shansius (AMNH 117337), left mandible with m1-m3. G. Brachyrhizomys shansius (IVPP 31.095), right mandible with m1-m3. H. Brachyrhizomys 
1

shansius (14183), fragment of right hemimandible with m2-m3. I. Brachyrhizomys shansius (IVPP 31.096), right mandible with $\mathrm{m} 1-\mathrm{m} 3$. Scale bar equals $4 \mathrm{~mm}$. C and D are redrawn after Flynn (1982a), G and I after Teilhard de Chardin (1942) and H after Flynn (1993). 

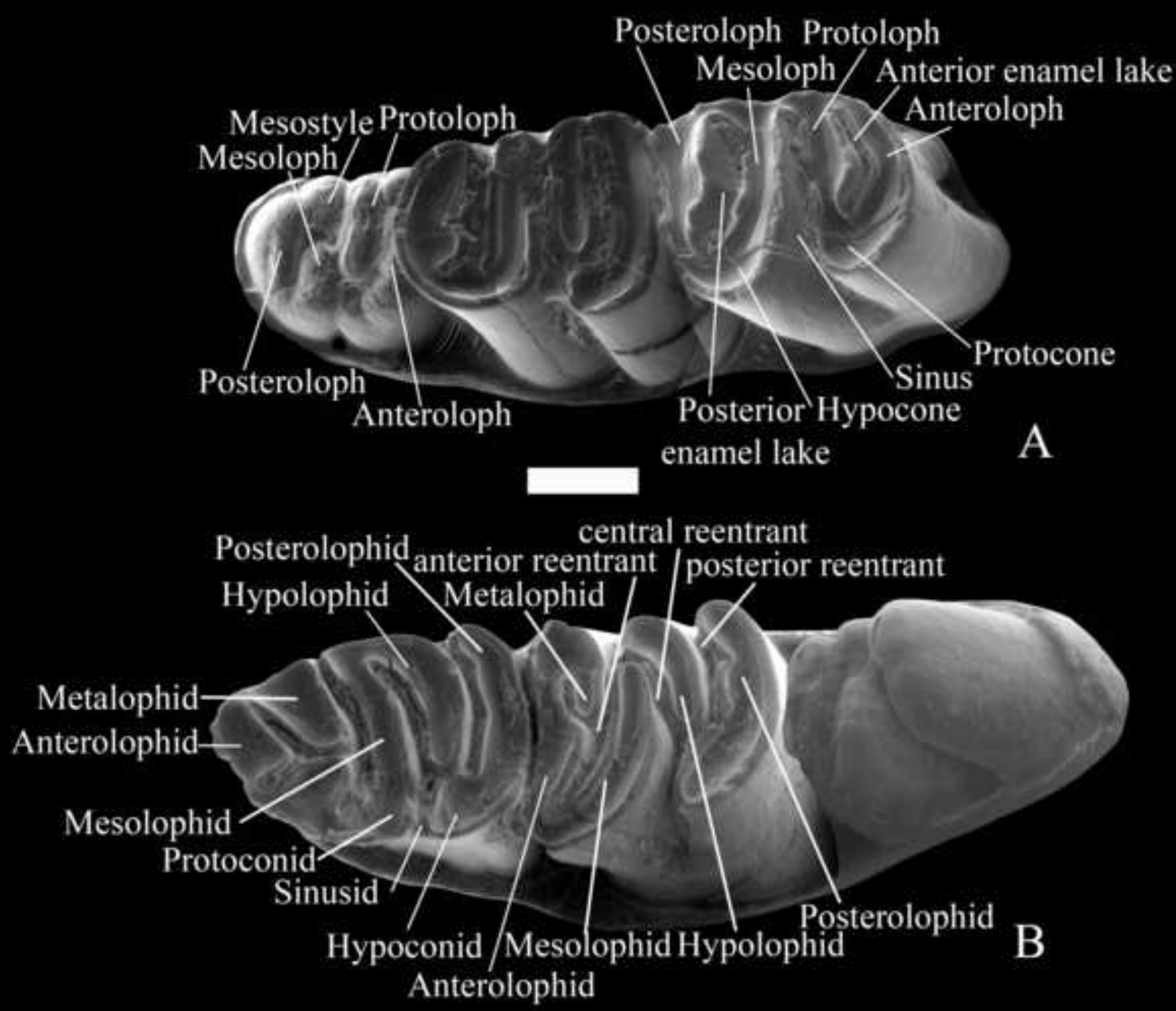
Click here to download high resolution image
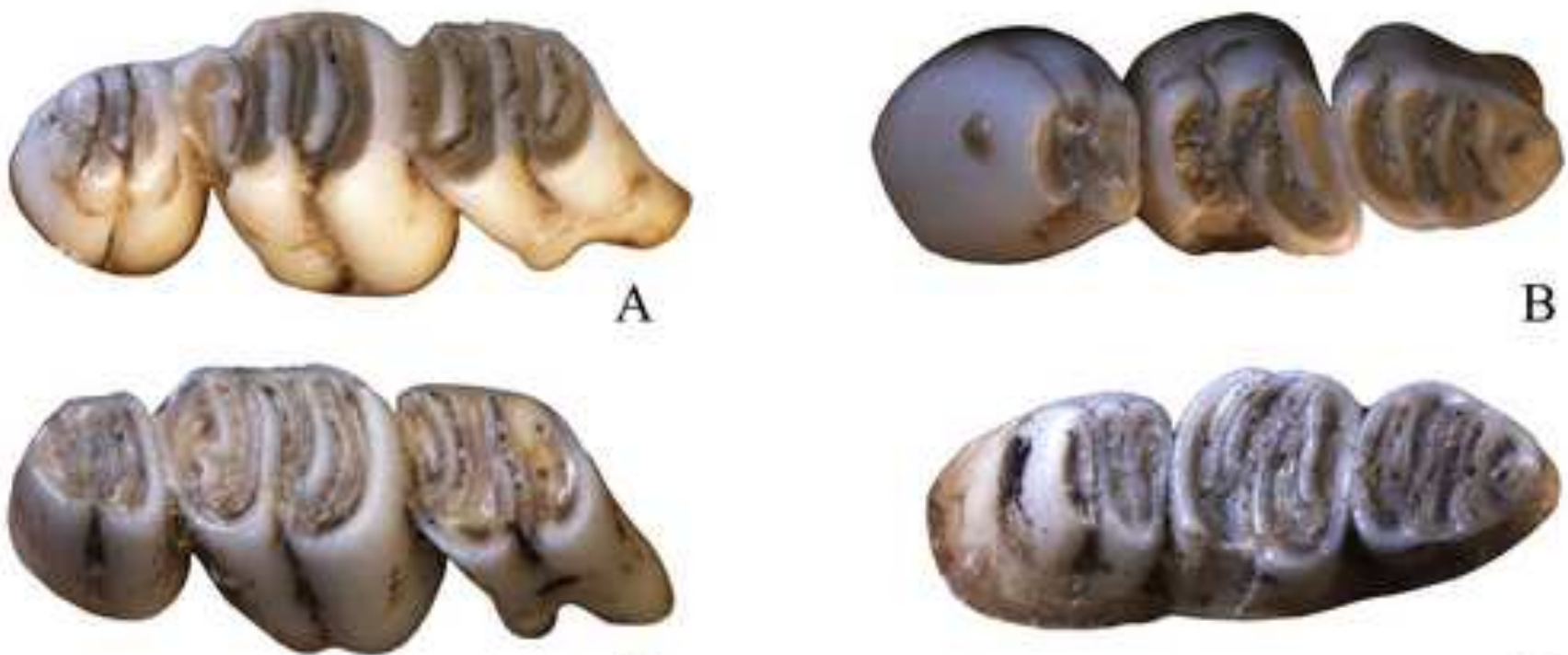

C

D

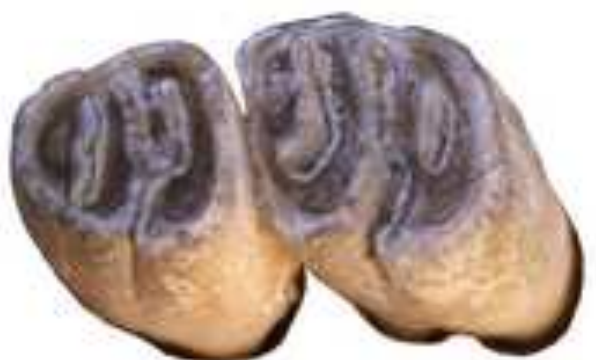

E
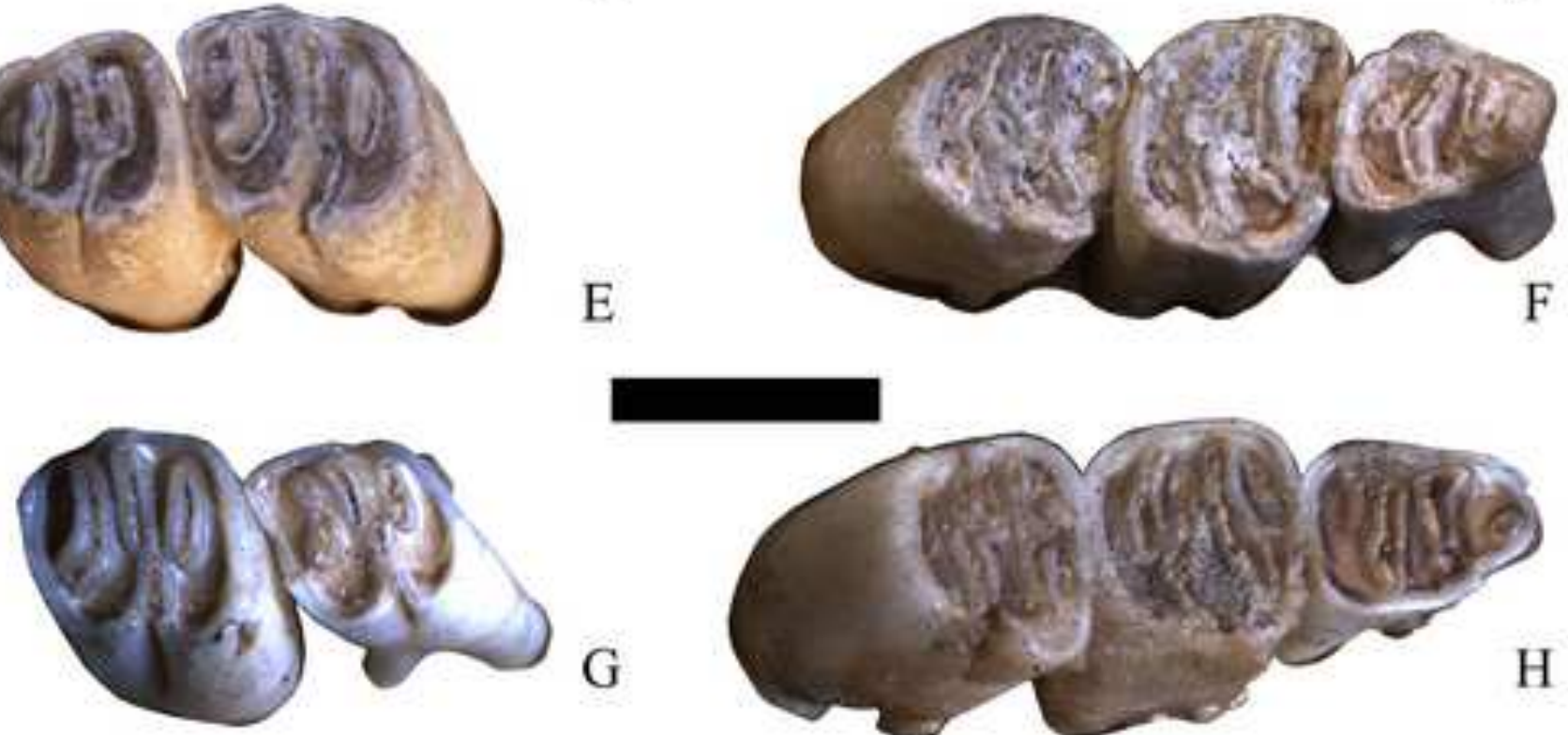

G
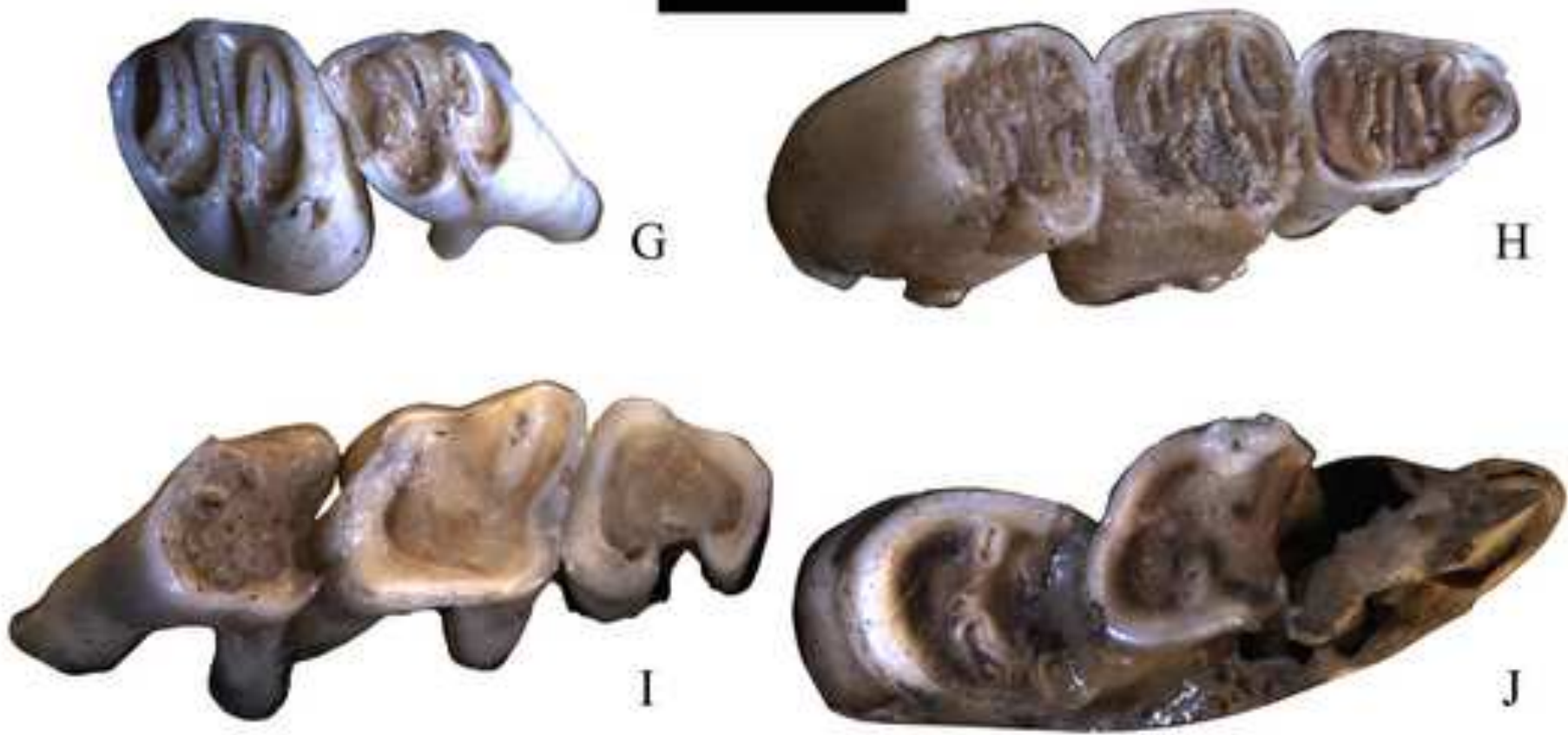
Click here to download high resolution image
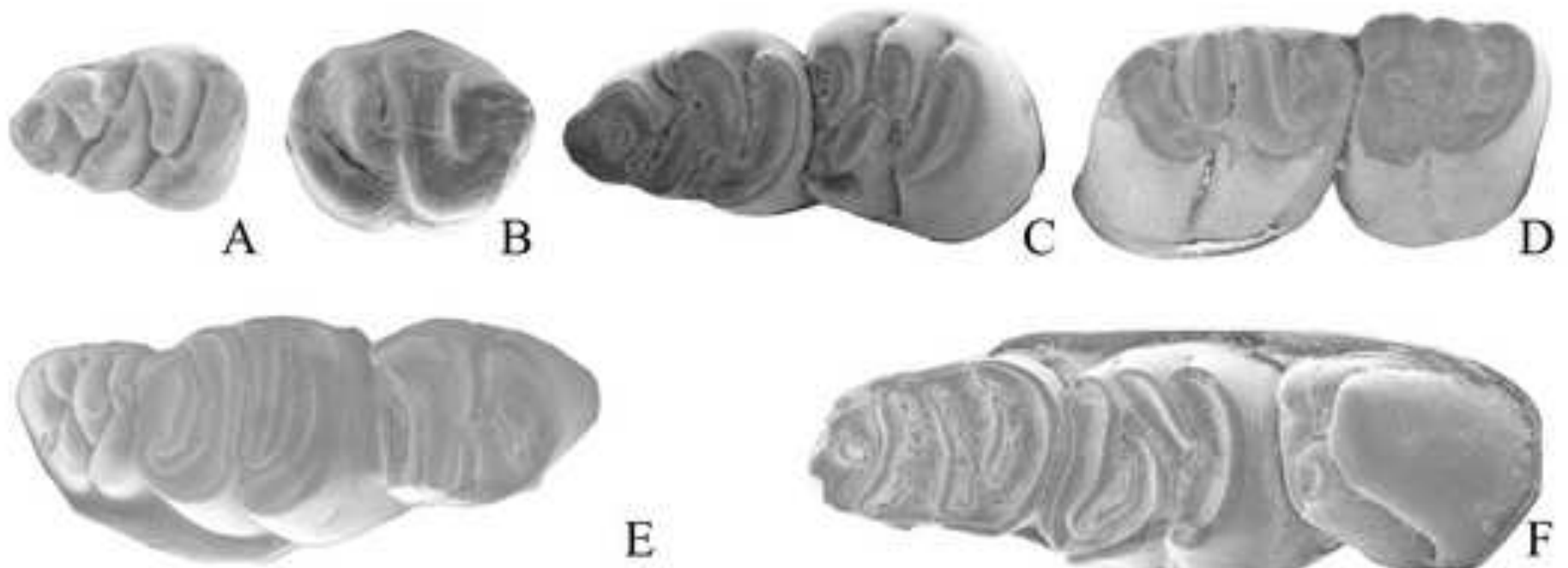

E
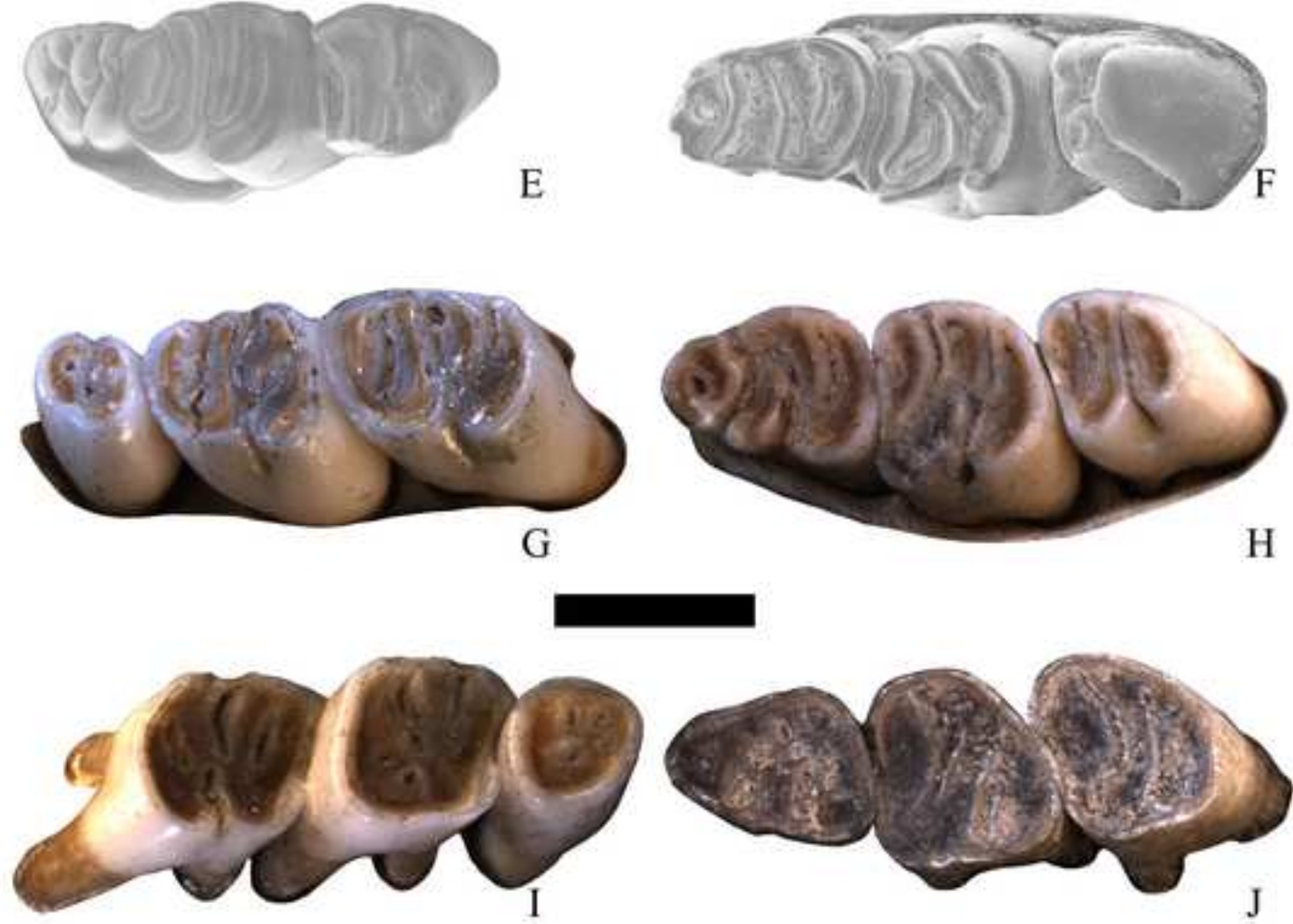
Click here to download high resolution image
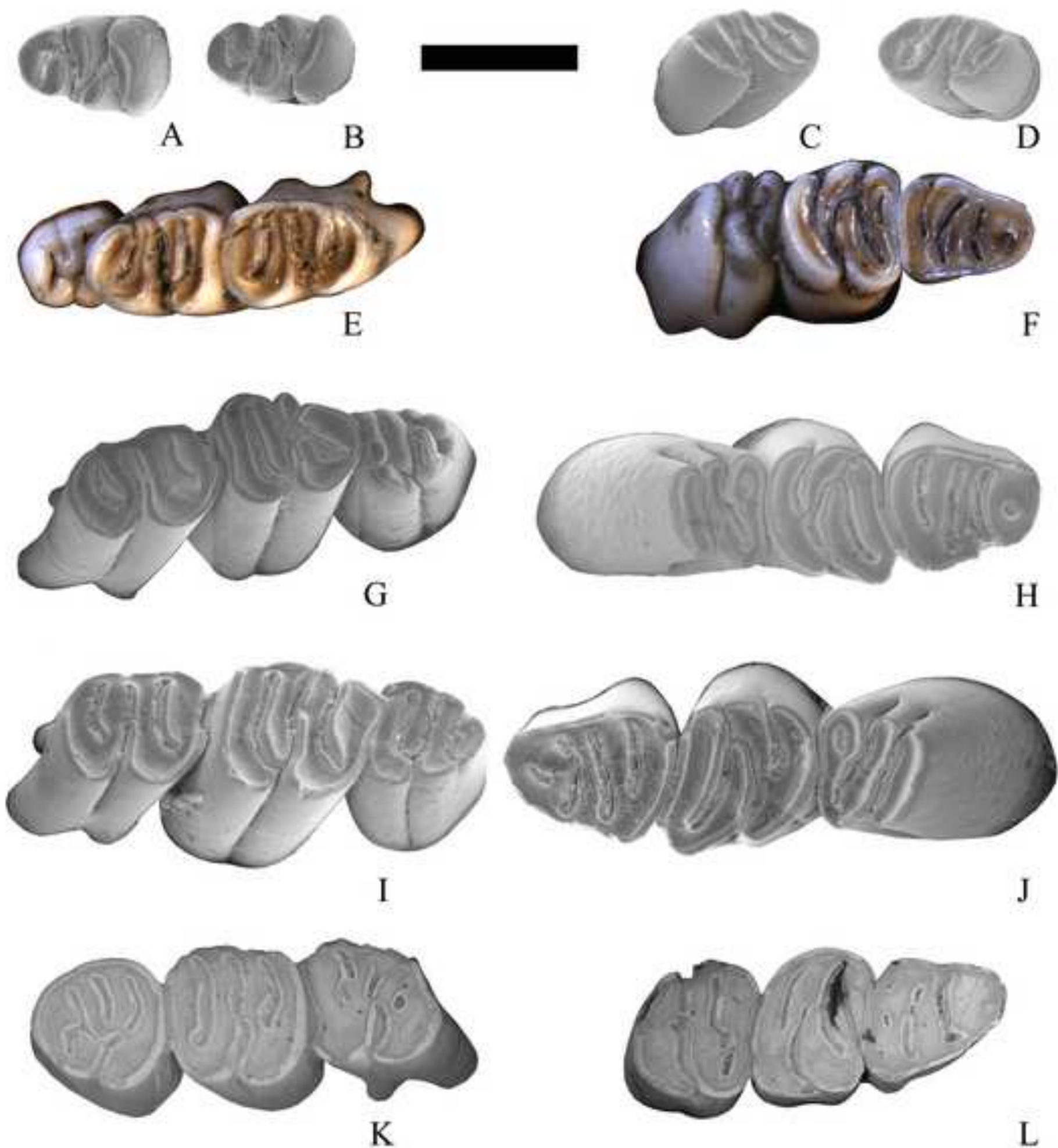

L
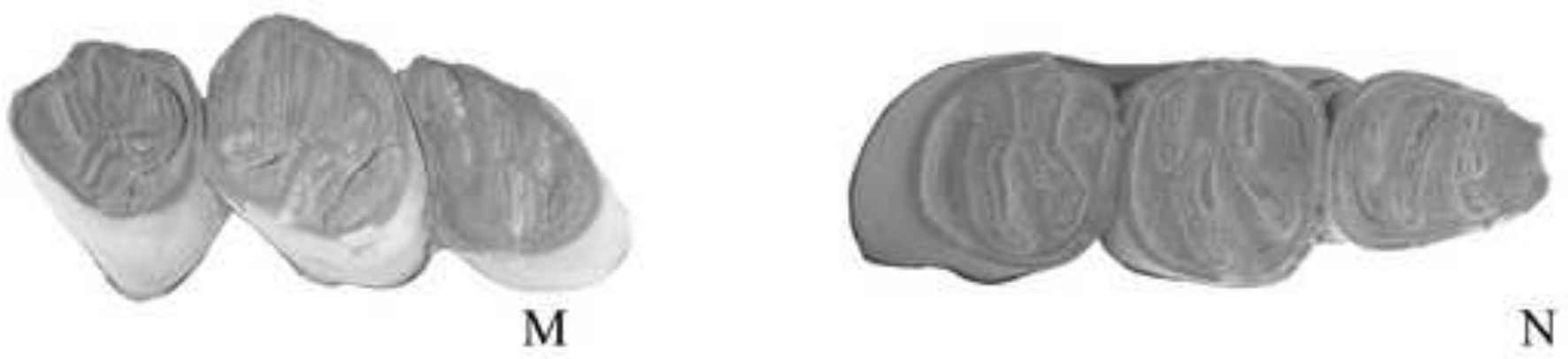
Click here to download high resolution image
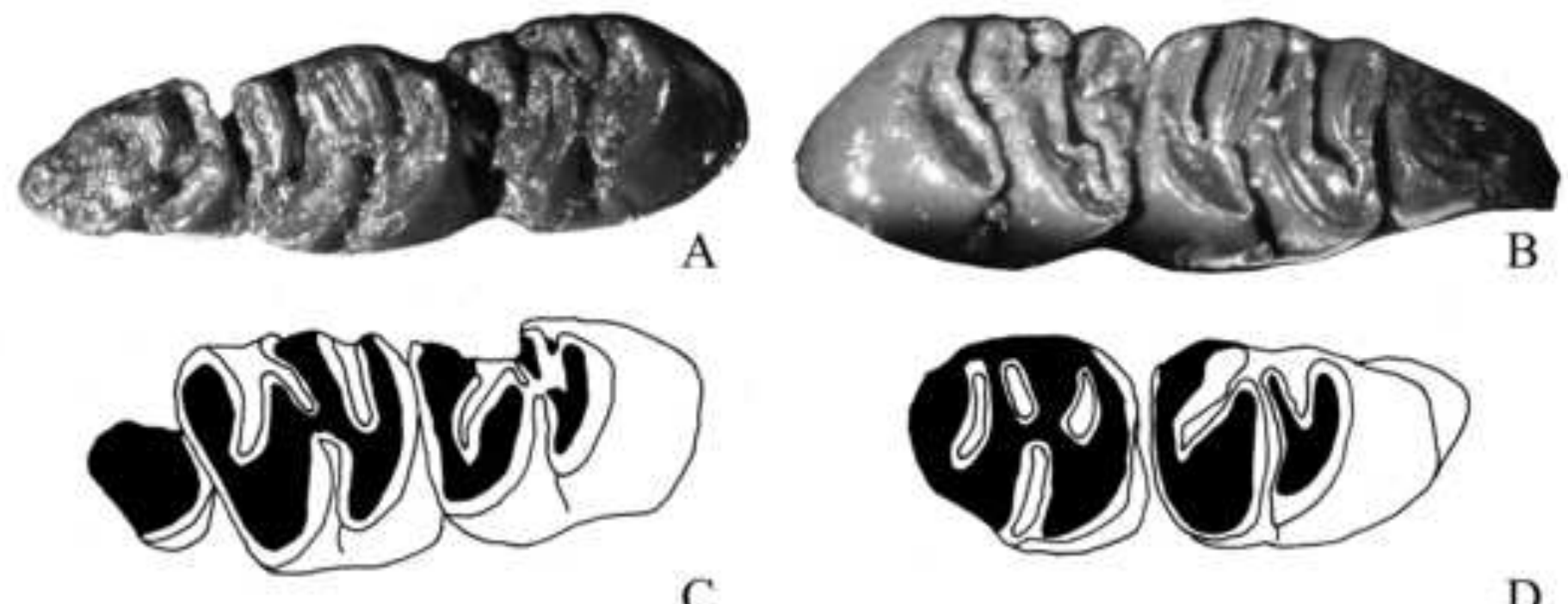

C
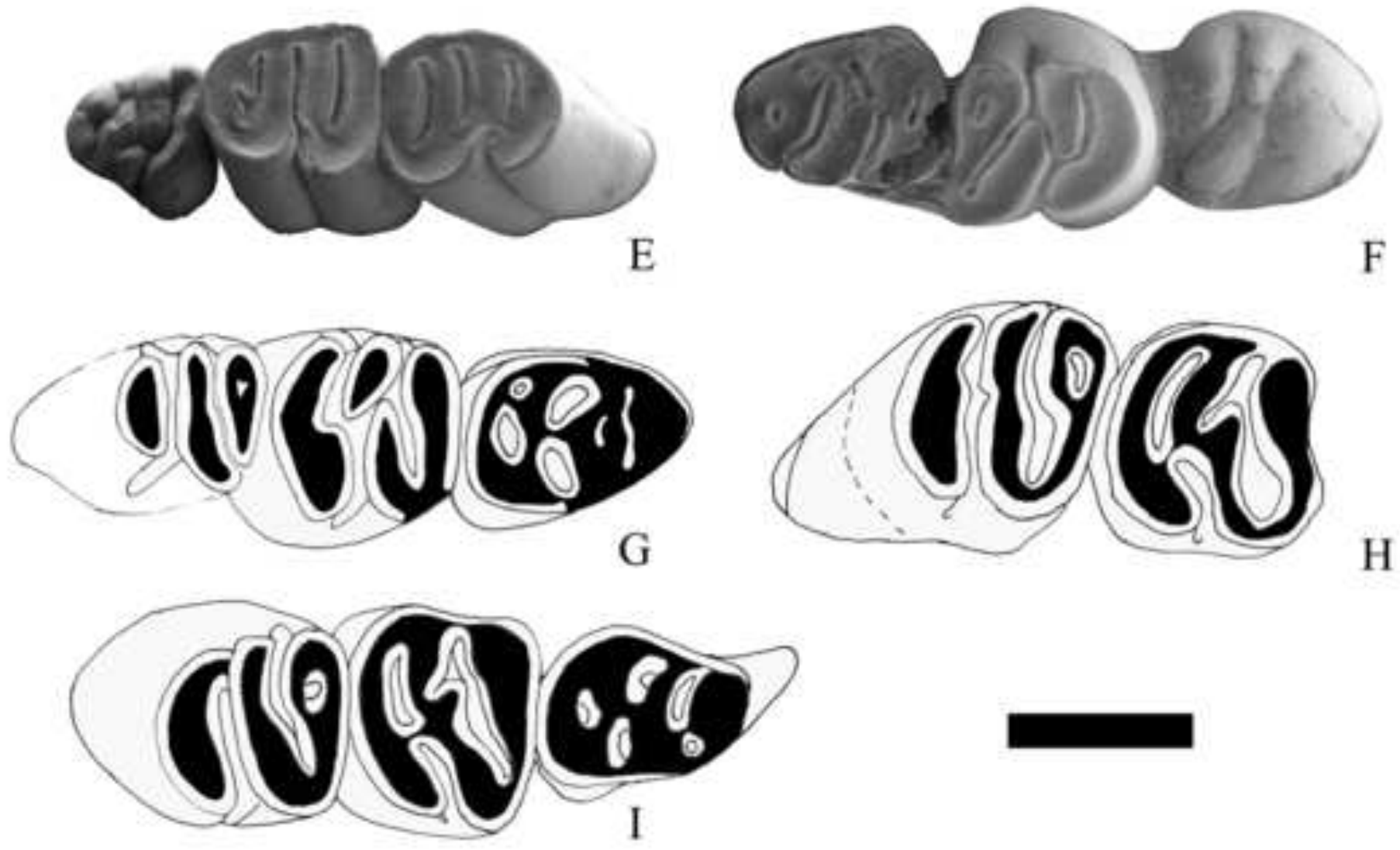

$\mathrm{H}$ 